\title{
COVID-19: How to Use a Jet Nebulizer for Drug Administration in Ventilated Patients without Putting the Healthcare Workers at Risk
}

\author{
Arieh Eden $^{a} \quad$ Tzipora Gashi $^{a} \quad$ Irina Bergman ${ }^{b}$ Dmitry Kompaniets ${ }^{a}$ \\ Avinoam Shiranc, d \\ aDepartment of Anesthesiology, Critical Care and Pain Medicine, Lady Davis Carmel Medical \\ Center, Haifa, Israel; ${ }^{b}$ Department of Medicine, Lady Davis Carmel Medical Center, Haifa, \\ Israel; ' Department of Cardiovascular Medicine, Lady Davis Carmel Medical Center, Haifa, \\ Israel; ${ }^{d}$ The Ruth and Bruce Rappaport Faculty of Medicine, Technion - Israel Institute of \\ Technology, Haifa, Israel
}

\section{What Is It about?}

- This letter describes a simple way to administer inhalations in ventilated patients without opening the circuit and creating aerosol. The method is particularly useful in COVID-19 patients to prevent infection of healthcare workers.

Dear Editor,

A jet nebulizer is frequently used in ventilated patients to administer inhalations with bronchodilators and hypertonic saline. In ventilated COVID-19 patients, this can be beneficial to reduce airway blockage with viscous secretions and to decrease the need for bronchoscopy due to airway obstruction. However, the use of a nebulizer requires frequent disconnections of the ventilator circuit. In ventilated COVID-19 patients, this action can greatly increase the risk of airborne infection for healthcare workers through aerosol formation. The SARS-CoV-2 virus can remain viable and infectious in aerosols for hours [1]. It has been recommended that nebulization of medications should be avoided in ventilated COVID-19 patients to reduce the risk of infection for healthcare workers [2].

Usually, the use of a nebulizer requires disconnection of the heat and moisture exchanger (HME) filter (located between the endotracheal tube and the ventilator circuit) and the nebulizer itself for each inhalation (Fig. 1, showing standard configuration). We propose using a one-way valve (BTS1241A; WILAmed GmbH, Kammerstein, Germany) in the nebulizer T-piece (Fig. 2), which will enable disconnection of the nebulizer cup for medication loading 
Biomedicine

Hub

Fig. 1. Standard nebulizer configuration. The nebulizer is located between the ventilator and the HME on the inspiratory line. HME, heat and moisture exchanger.

\begin{tabular}{l|l}
\hline Biomed Hub 2020;5:508845 \\
\hline DOI: 10.1159/000508845 & $\begin{array}{l}\text { @ 2020 The Author(s). Published by S. Karger AG, Basel } \\
\text { www.karger.com/bmh }\end{array}$ \\
\hline
\end{tabular}

Eden et al.: Using a Nebulizer in COVID-19
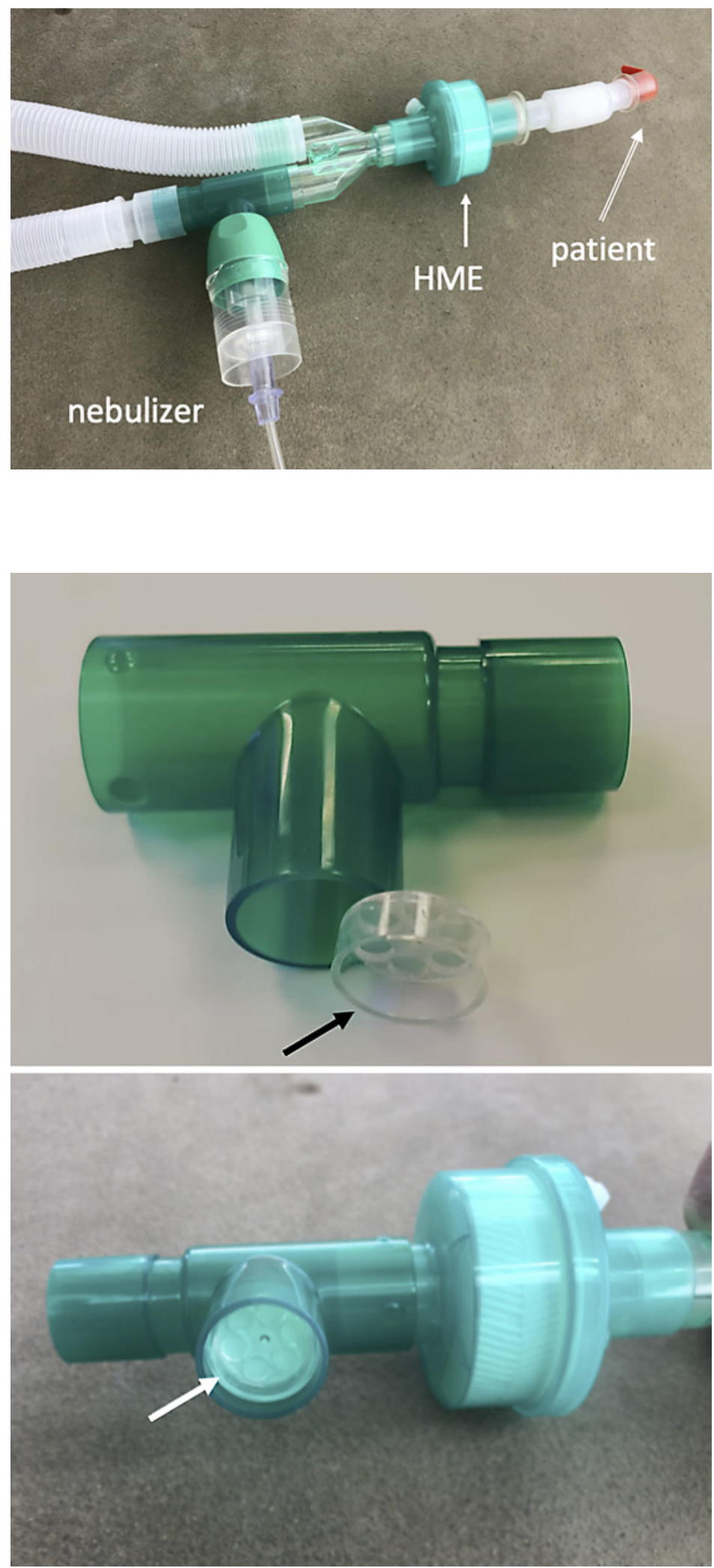

Fig. 2. The one-way valve (arrow) in position in the T-piece (bottom). 
Fig. 3. Disconnection of the nebulizer cup without producing aerosol leak. The ventilator screen is showing zero leak from the ventilator tubing (red circle) while the nebulizer cup is disconnected (arrow) and the one-way valve is in place.

Fig. 4. Proposed configuration. The HME filter is located proximal to the nebulizer T-piece. HME, heat and moisture exchanger.
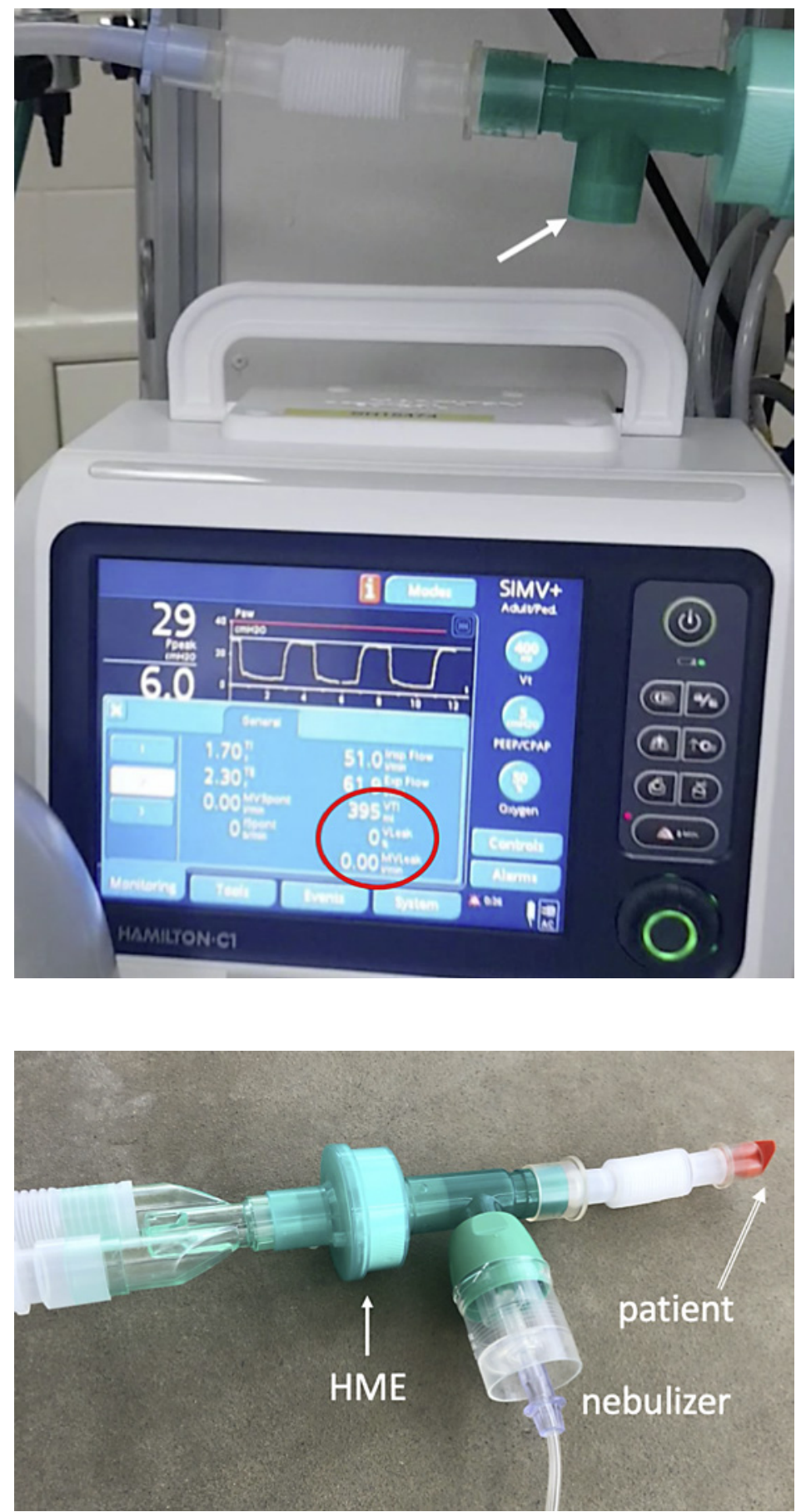

without producing aerosol leak from the ventilator (Fig. 3). We also suggest placing the HME filter proximal to the nebulizer T-piece, between the T-piece and the ventilator circuit (Fig. 4), thus enabling the use of the nebulizer without disconnecting the filter. The increase in dead space associated with this configuration is negligible $(25 \mathrm{~mL})$. One should make sure that the one-way valve is oriented correctly, enabling flow from the nebulizer cup into the T-piece and not vice versa. We have started using this method for inhalation therapy in our mechanically ventilated COVID-19 patients. 
In conclusion, we suggest using a simple, widely available, one-way valve to enable safe inhalations with a nebulizer in ventilated COVID-19 patients without the risk of airborne infection for healthcare providers.

\section{Disclosure Statement}

The authors have no conflicts of interest to declare.

\section{Author Contributions}

A.E: conception of idea, testing, drafting of the manuscript and revision; T.G: conception of idea, testing, revision; I.B: revision; D.K: testing, revision; A.S: drafting and revision.

\section{References}

1 van Doremalen N, Bushmaker T, Morris DH, Holbrook MG, Gamble A, Williamson BN, et al. Aerosol and Surface Stability of SARS-CoV-2 as Compared with SARS-CoV-1. N Engl J Med. 2020 Apr;382(16):1564-7.

2 Wax RS, Christian MD. Practical recommendations for critical care and anesthesiology teams caring for novel coronavirus (2019-nCoV) patients. Can J Anesth. 2020 May;67(5):568-76. 